\title{
A PARTICIPAÇÃO DAS ONG'S NOS ACORDOS MULTILATERAIS AMBIENTAIS: UMA ANÁLISE DA CONVENÇÃO SOBRE O COMÉRCIO INTERNACIONAL DE ESPÉCIES DA FLORA E DA FAUNA SELVAGENS AMEAÇADAS DE EXTINÇÃO (CITES)
}

\author{
PARTICIPATION OF NGOS IN MULTILATERAL ENVIRONMENTAL AGREEMENTS: \\ AN ANALYSIS OF THE CONVENTION ON INTERNATIONAL TRADE IN \\ ENDANGERED SPECIES OF WILD FAUNA AND FLORA (CITES)
}

\begin{abstract}
Lívia Gaigher Bósio Campello
Pós-Doutora em Direito do Estado pela Universidade de São Paulo - USP. Professora Adjunta da Universidade Federal de Mato Grosso do Sul (UFMS). Professora permanente do Programa de Mestrado em Direitos Humanos da UFMS. Editora-chefe da Revista Direito UFMS. Coordenadora do Projeto de Pesquisa Cooperação Internacional e Meio Ambiente MS/FUNDECT. Vice-presidente da Comissão de Pesquisa e Pós-Graduação da

OAB/SP. E-mail: livia.gaigher@uol.com.br
\end{abstract}

Convidada

Doi: $10.5585 / \mathrm{rdb} . v 14 \mathrm{i} 6.444$

RESUMO: Diante da necessidade de democratização da elaboração e implementação das políticas internacionais ambientais, nomeadamente em função da ampla compreensão do meio ambiente como interesse da sociedade mundial e objeto de cooperação, paradigmas que se tornaram mais fortes com a aceleração do processo de globalização, as organizações não governamentais (ONG's) se afirmaram como atores legítimos cada vez mais influentes nesse processo ao longo das duas últimas décadas do século XX. As regras e práticas consagradas em várias instituições internacionais modernas demonstram consideráveis oportunidades e direitos de participação, tal como este estudo revela à luz do regime estabelecido pela Convenção sobre o Comércio Internacional de Espécies da Flora e da Fauna Selvagens Ameaçadas de Extinção (CITES). Contudo, alguns obstáculos à participação podem ser ainda postos à reflexão para futuros desenvolvimentos, por exemplo, a necessidade de maior abertura à participação em órgãos de decisão, a real função da análise prévia de documentos encaminhados pelas ONG's nas reuniões oficiais, a necessidade de distinção entre ONG's nacionais e internacionais, a exigência de instrumentos de equidade na contratação de serviços para as instituições internacionais e, finalmente, a falta de mecanismos de financiamento para representação dos países em desenvolvimento. Com efeito, anomalias de fato existem e requerem soluções. Todavia, devido às tendências introduzidas pela CITES, em especial pela codificação de novas regras de participação com base no forte consenso histórico de que as ONG's são importantes parceiras nas formulação e implementação dos regimes internacionais ambientais, a expectativa é alta em favor de novas evoluções e paradigmas para a participação nos regimes multilaterais ambientais.

Palavras-Chave: Organizações não governamentais (ONG'S). Direitos de participação. Regimes internacionais ambientais. Convenção sobre o Comércio Internacional de Espécies da Flora e da Fauna Selvagens Ameaçadas de Extinção (CITES).

ABSTRACT: Considering the need to democratization of the development and implementation of international environmental policies, notably by reference of the broad understanding of the environment as the interest of world society and cooperation object, paradigms that have become 
stronger with the acceleration of globalization, non-governmental organizations (NGOs) asserted themselves as legitimate actors increasingly influential in this process over the last two decades of the twentieth century. The rules and practices enshrined in various modern international institutions demonstrate enormous opportunities and participation rights, as this study reveals about the regime established by the Convention on International Trade in Endangered Species of Wild Fauna and Flora (CITES). However, some barriers to participation may still be put to reflection for future developments, for example, the need for increased opening to participation in decision-making bodies, the actual function of the preliminary analysis of documents submitted by NGOs in official meetings, the need of distinction between national and international NGOs, the demand for equitable instruments for contracting services for international institutions and finally the lack of funding mechanisms for the representation of developing countries. In effect, anomalies exist and require solutions. However, because of the tendencies introduced by CITES, in particular the codification of new rules for participation based on strong historic consensus that NGOs are important partners in the formulation and implementation of international environmental regimes, the expectation is high in favor of new developments and paradigms for participation in multilateral environmental regimes.

Keywords: Non-governmental organizations (NGOs). Participation rights. International environmental regimes. Convention on International Trade in Endangered Species of Wild Fauna and Flora (CITES).

SUMÁRIO: Introdução; 1. As ONG's e sua legitimidade na governança internacional ambiental; 1.1. Princípios emergentes da participação das ONG's no direito internacional do meio ambiente; 1.2. Legitimidade das ONG's, democracia e representatividade; 2. ONG's: Conceito, classificação e funções; 3. Participação das ONG's nos acordos multilaterais ambientais (AMA's): uma análise da CITES; 3.1. Acreditação e acesso às reuniões; 3.2. Participação ativa nas reuniões; 3.3. Apresentação, distribuição de documentos e disseminação de informação; Conclusão; Referências Bibliográficas.

\section{INTRODUÇÃO}

A relevância das organizações não governamentais (ONG's) nos regimes internacionais ambientais tem aumentado consideravelmente desde as duas últimas décadas, em função da ampla compreensão do meio ambiente como interesse da sociedade e objeto de cooperação internacional, paradigmas que se tornaram ainda mais evidentes com a aceleração do processo de globalização. A crescente influência de entidades não estatais nos rumos do desenvolvimento recente do ordenamento jurídico internacional aparece como uma das características mais marcantes da evolução do direito internacional, revelando um processo de mitigação da faceta puramente interestatal que este possuíra um dia. Com a rediscussão da posição e do papel do Estado no ordenamento jurídico internacional, foi possível ao direito internacional do meio ambiente estipular uma limitação cada vez mais profunda aos direitos soberanos desses entes estatais, bem como uma cooperação institucional cada vez mais efetiva.

Nesse contexto, a participação das ONG's tornou-se um assunto importante para investigação resultando em um corpo crescente de literatura tanto nas ciências jurídicas como nas ciências sociais. Apesar disso, é possível verificar que o esforço para sistematizar e analisar a relação jurídica e a influência prática das ONG's nos acordos multilaterais ambientais tem sido limitado. Isso se deve às dificuldades de pesquisar um objeto que constantemente influencia e é influenciado por uma gama de domínios políticos. Sob tais circunstâncias, a investigação sobre as ONG's e sua relação com os acordos multilaterais ambientais requer, não apenas conhecimento jurídico sobre os direitos e obrigações estabelecidos nos regimes internacionais, mas igualmente 
o entendimento de fundo acerca do processo político de formação destes instrumentos no âmbito das instituições internacionais e sobretudo sua relação com os pressupostos de legitimidade e participação democrática.

Com esta perspectiva, este estudo intenta apresentar um balanço do estado atual da participação das ONG's nos regimes internacionais ambientais, desenhado pelas normas positivadas nos diversos acordos multilaterais ambientais e também a partir das definições, princípios e práticas da governança internacional ambiental, construídas no âmbito das atuais instituições internacionais. Mais especificamente, procura analisar com detalhe a base jurídica da participação das ONG's à luz do regime estabelecido pela Convenção sobre o Comércio Internacional de Espécies da Flora e da Fauna Selvagens Ameaçadas de Extinção (CITES). Isso se justifica pelo fato de que este regime pode ser considerado entre os mais modernos e liberais dentre os tratados ambientais em termos de participação das ONG's, sendo que algumas de suas disposições sobre participação foram repercutidas em outros tratados multilaterais ambientais. Há no seu complexo processo de formação e implementação, aspectos instigantes e positivos que merecem ser examinados, como o elevado nível de positivação normativa, abertura de precedentes institucionais e forte consenso internacional sobre a importância da parceria das organizações não governamentais, mas também há que ser identificados obstáculos à participação, os quais necessitam ser dimensionados em seu contexto para que sejam viáveis algumas propostas de solução.

\section{AS ONG'S E SUA LEGITIMIDADE NA GOVERNANÇA INTERNACIONAL AMBIENTAL}

O papel das ONG's na política internacional ambiental não pode ser considerado um fim em mesmo e nem sequer ser desempenhado sem limites. Em que consiste, então, o papel das ONG's na formulação de políticas? Como as ONG's devem contribuir para a governança internacional ambiental? Quais os limites para as funções que as ONG's estão autorizadas a desempenhar? Em suma, até que ponto a participação das ONG's pode ser considerada legítima?

$\mathrm{O}$ conceito de legitimidade é geralmente aplicado no âmbito dos sistemas políticos. Conforme Bernstein ${ }^{1}$, legitimidade pode ser definida como "aceitação e justificação de regras compartilhadas pela comunidade". Nessa perspectiva, é empregado como condição para que uma decisão coletiva seja vinculante. Ao contrário da legalidade, que está relacionada a uma ação legal, a legitimidade política é entendida como construção a partir de valores e regras comuns reconhecidas por cidadãos. Com relação à ONG e sua participação na governança internacional ambiental, o conceito de legitimidade possui uma importante dimensão, que é a contribuição para o aumento da democratização na tomada da política internacional.

Uma vez que a legitimidade é um conceito que depende de valores e percepções que estão sujeitas a mudanças ao longo do tempo, qualquer discussão sobre a legitimidade da participação das ONG's só pode, portanto, produzir resultados preliminares. No estudo que segue, duas fontes de orientação são relevantes: (a) os instrumentos estabelecidos na legislação e na política internacional ambiental e (b) a doutrina sobre a participação das ONG's, enraizada especialmente na teoria democrática.

\footnotetext{
${ }^{1}$ BERNSTEIN, S. Legitimacy in Global Environmental Governance. In: Journal of International Law and International Relations 1, 2005. pp. 139-166. Ver, também, BODANSKY, Daniel. The Legitimacy of International Governance: A Coming Challenge for International Environmental Law? In: The American Journal of International Law. Vol. 93, N. 3, 1999. pp. 596-624
} 


\subsection{PRINCÍPIOS EMERGENTES DA PARTICIPAÇÃO DAS ONG'S NO DIREITO INTERNACIONAL DO MEIO AMBIENTE}

A participação das ONG's na formulação de políticas públicas ambientais foi estabelecida a nível global, tanto na Declaração do Rio sobre Meio Ambiente e Desenvolvimento como na Agenda 21, durante a Conferência das Nações Unidas sobre Meio Ambiente e Desenvolvimento em 1992. Além desses importantes instrumentos, também há que se mencionar a Convenção de Aarhus de 1998 sobre o Acesso à Informação, Participação Pública no Processo de Tomada de Decisão e Acesso à Justiça em Matéria de Meio Ambiente ${ }^{2}$. A Convenção de Aarhus, negociada no âmbito da Comissão Econômica das Nações Unidas para a Europa (UNECE), tem apenas âmbito regional e, embora vise os processos políticos domésticos, seus princípios refletem uma tendência mais ampla na ordem internacional e devem, portanto, ser analisados no contex to deste estudo.

A Declaração do Rio, que estabelece um quadro importante para futuros desenvolvimentos em direito internacional do meio ambiente, em seu Princípio 10, afirma de forma muito ampla que as questões ambientais são melhor tratadas com a participação de todos cidadãos interessados, no nível adequado. E, por conseguinte, reconhece a importância da participação pública incluindo a atuação das ONG's.

Um pouco mais específica, a Agenda 21, a qual estabelece um plano de ação para a realização dos objetivos da Declaração do Rio, afirma que um dos pré-requisitos fundamentais para a concretização do desenvolvimento sustentável é a ampla participação pública na tomada de decisões. Com base no Princípio 10 da Declaração do Rio, a Agenda 21 dedica um capítulo inteiro para as ONG's e o fortalecimento de seu papel como "parceiros para o desenvolvimento sustentável"3. Sendo assim, a Agenda 21 reconhece que as ONG's desempenham um papel vital na formação e implementação da democracia participativa, que a sua natureza independente exige uma participação genuína e que a sua credibilidade advém do papel responsável e construtivo que desempenham na sociedade ${ }^{4}$. Além disso, a máxima comunicação e cooperação entre as ONG's, organizações internacionais e governos nacionais deve ser implementada para assegurar que sua contribuição potencial se materialize ${ }^{5}$.

A Agenda 21 destaca a importância da participação de ONG's em dois particulares aspectos. Em primeiro lugar, considera a participação das ONG's como importante contribuição para uma democratização dos processos políticos, tanto em nível nacional como na arena internacional $^{6}$. Em segundo lugar, destaca a relevância da contribuição das ONG's no aprimoramento do processo de revisão e aplicação das políticas, devido a sua experiência e conhecimento especializado ${ }^{7}$.

A Convenção de Aarhus exige que cada parte promova a aplicação dos princípios da Convenção nos processos de tomada de decisões ambientais e no quadro das organizações internacionais em matérias relativas ao meio ambiente ${ }^{8}$. A este respeito, a Convenção de Aarhus estabelece três princípios: o acesso à informação, a participação pública na tomada de decisões e

\footnotetext{
${ }^{2}$ Cumpre acrescer que as discussões sobre governança internacional ambiental, lideradas pelo Programa das Nações Unidas para o Meio Ambiente - PNUMA, já no início do século XXI, confirmaram a crescente importância de se conceder direitos de participação à sociedade civil e às organizações não governamentais. Entre outras ações, foi elaborada uma estratégia para o reforço do envolvimento da sociedade civil no trabalho do PNUMA. Ver, nesse sentido, UNITED NATIONS. Decision SS.VII/5. Enhancing civil society engagement in the work of the United Nations Environment Programme. UNEP/GCSS.VII/6 e UNEP/GCSS.VII/4/Add.1.

${ }^{3}$ Conforme capítulo 27 da Agenda 21.

${ }^{4}$ Conforme capítulo 27 (27.1) da Agenda 21.

${ }^{5}$ Conforme capítulo 27 (27.4) da Agenda 21.

${ }^{6}$ Conforme capítulo 27 (27.1) da Agenda 21.

${ }^{7}$ Conforme capítulo 27 (27.3) da Agenda 21.

${ }^{8}$ Conforme artigo $3^{\circ}(7)$ da Convenção de Aarhus.
} 
acesso à justiça. Nesse sentido, a Convenção reflete os objetivos de implementação do Princípio 10 da Declaração do Rio a nível regional e sua relevância, portanto, se estende além da região abrangida pela UNECE, uma vez que oferece um modelo para aplicação do Princípio 10 da Declaração.

$\mathrm{O}$ acesso à informação significa que os cidadãos têm o direito de obter informação ambiental das autoridades públicas, sem ter de demonstrar um interesse ${ }^{9}$, o que pode ser limitado por exceções claramente definidas, a exemplo da necessidade de confidencialidade dos procedimentos das autoridades públicas ${ }^{10}$. Em diversas instituições internacionais ambientais este princípio pode ser observado em sua prática cotidiana. Por exemplo, a documentação relativa à Convenção sobre o Comércio Internacional de Espécies da Flora e da Fauna Selvagens Ameaçadas de Extinção (CITES) está geralmente disponível para todos os interessados na página da internet do secretariado.

No que diz respeito à participação pública na tomada de decisões, a Convenção de Aarhus diferencia entre atividades específicas ${ }^{11}$, planos, programas e políticas ambientais ${ }^{12} \mathrm{e}$ preparação de regulamentos e/ou instrumentos normativos legalmente vinculativos ${ }^{13}$. Nesses termos, prevê que as Partes se esforcem para promover uma participação pública efetiva. O princípio da participação pública na tomada de decisões também se reflete na prática de muitas instituições internacionais relevantes para o meio ambiente. Assim, a grande maioria dos acordos multilaterais ambientais concedem formalmente o acesso a reuniões formais e permitem a participação ativa nas deliberações.

Em terceiro lugar, a Convenção de Aarhus obriga as Partes a estabelecerem mecanismos de controle jurisdicional de modo que as violações do acesso à informação possam ser $\operatorname{contestadas}^{14}$. Com efeito, a Convenção afirma a importância do acesso à justiça em face às recusas do acesso à informação, mas deixa os critérios e outros desafios para a legislação nacional. Enquanto que as instituições internacionais em matéria de meio ambiente, em geral, não dispõem de procedimentos formais para queixas sobre obstrução do acesso à informação, cada vez mais é concedido às ONG's algum tipo de mecanismo para avaliar e operar nos procedimentos de execução dos acordos multilaterais ambientais ${ }^{15}$. Nesse sentido, muitos acordos permitem explicitamente que as ONG's enviem informações aos órgãos de execução ou à secretaria, como uma forma de potencial gatilho para um caso de existente violação.

\subsection{LEGITIMIDADE DAS ONG'S, DEMOCRACIA E REPRESENTATIVIDADE}

O crescente papel dos atores não governamentais tem sido retratado no cenário da política internacional como uma real contribuição para democratização da elaboração de políticas. Com o advento do que tem sido chamado de "nova diplomacia"16 ou "multilateralismo complexo" "17 os governos nacionais tendem a perder o seu monopólio sobre a política externa. A perspectiva em que insurge o conceito de "sociedade civil mundial ou global" não é de oposição

\footnotetext{
${ }^{9}$ Conforme artigo $4^{\circ}$ da Convenção de Aarhus.

${ }^{10}$ Conforme artigo $4^{\circ}$ (4.a) da Convenção de Aarhus.

${ }^{11}$ Conforme artigo $6^{\circ}$ da Convenção de Aarhus.

${ }^{12}$ Conforme artigo $7^{\circ}$ da Convenção de Aarhus.

${ }^{13}$ Conforme artigo $8^{\circ}$ da Convenção de Aarhus.

${ }^{14}$ Conforme artigo $9^{\circ}$ da Convenção de Aarhus.

15 BOMBAY, Peter. The Role of NGOs in Shaping Community Positions in International Environmental Fora. In: Review of European Community and International Environmental Law. Vol. 10, N. 2, 2001. pp. 164-165.

${ }^{16}$ ANNAN, Kofi. The Quiet Revolution. In: Global Governance. N. 4, 1998, pp. 123-138.

${ }^{17}$ O'BRIEN, Robert, et alli. Contesting Global Governance. Multilateral Economic Institutions and Global Social Movements. Cambridge: Cambridge University Press. 2000.
}

Revista de Direito Brasileira | São Paulo, SP | v. 14 | n. 6 | p. 89 - 108 | maio/ago. 2016 
ao Estado, à democratização ou integração nacional, mas a da "ordem mundial emergente"18. Nesse sentido, o discurso sobre a sociedade civil de fato se mundializou e, assim, surgiu uma grande expectativa em torno das ONG's internacionais como associações que tendem a desempenhar um papel cada vez maior nas negociações multilaterais ${ }^{19}$.

As ONG's muitas vezes representam interesses e valores que ultrapassam as fronteiras políticas nacionais. Nessa linha, podem fornecer serviços, como monitoramento e prestação de informações, que os governos e as instituições internacionais muitas vezes não conseguem realizar, o que de fato contribui para a sua legitimidade na contribuição efetiva para solução dos problemas. De outro ângulo, ao se oportunizar a voz às partes interessadas abastece-se o debate global com aumento da transparência e da responsabilidade pública. Ademais, no âmbito das instituições internacionais, as ONG's podem reduzir o déficit democrático, no que concerne ao sistema de governança internacional, por meio da gênese de uma esfera pública transnacional, que funciona como espécie de corretivo às negociações internacionais em geral bastante fechadas.

Em contraste com esta contribuição positiva para democratização da política internacional, uma série de debates tem desafiado o papel das ONG's na formulação da política internacional, apontando para o fato de que as ONG's não possuem um mandato democrático, ou seja, para o qual haja eleição, e também não representam as pessoas de todo o mundo. $\mathrm{Na}$ verdade, devido ao domínio do Norte ocidental existem desequilíbrios geográficos e culturais que irradiam para os processos de negociação internacional, o que pode levar a conclusão de que as ONG's estariam longe de ser representantes de uma "sociedade civil global".

O movimento ambientalista é uma grande expressão do sentido e magnitude destas novas manifestações políticas, como observa Renato Ortiz ${ }^{20}$, o objeto do movimento ecológico, a Terra, ultrapassa as fronteiras nacionais dos Estados, pois "a preocupação ecológica não tem pátria, seu enraizamento é o planeta", por isso, apresenta-se como uma espécie de movimento da sociedade civil mundial. Nesse sentido, uma parte desta tensão tende a desaparecer após a constatação de que as ONG's representam preocupações de grupos, mas há interesses que ultrapassam as suas próprias preocupações, como no caso do interesse das futuras gerações, tal qual as ONG's ambientais que representam o interesse comum das gerações atuais e futuras em matéria de proteção ambiental e desenvolvimento sustentável. Todavia, o fato de representar os interesses da sociedade não significa a mesma representação de interesse público que traz como exigência a existência de um mandato. É bem verdade que em qualquer sistema democrático há que se oferecer oportunidades para os grupos interessados de participar do processo de decisão política até mesmo sem necessidade de um mandato eletivo. Nesse passo, não há nada de errado com a concessão do direito à voz às ONG's nos encaminhamentos e formulação das políticas internacionais ambientais. Em contrapartida, o direito formal ao voto, ou seja, o poder de decisão,

\footnotetext{
${ }^{18}$ COHEN, Jean L. Sociedade Civil e Globalização: repensando categorias. In: DADOS - Revista de Ciências Sociais. Vol. 46, N. 3, 2003. p. 419.

${ }^{19}$ Nesse sentido, expressa o Relatório da Assembleia Geral da ONU, A/53/170, de 10 de julho de 1998, sobre a participação das organizações não governamentais no sistema das Nações Unidas: "A atividade dos agentes não estatais se converteu em uma dimensão fundamental da vida pública em todo o mundo. Assim, a reforma e reestruturação das Nações Unidas coincidem com a aparição de um novo sistema internacional participativo que responde às forças de mundialização que imperam hoje no mundo. A crescente influência e o papel cada vez mais importante dos agentes não estatais tem sido um símbolo e uma causa da transformação que está experimentando nosso plano internacional. As organizações não governamentais são a manifestação mais clara do que se convencionou chamar 'sociedade civil', isto é, a esfera na qual os movimentos sociais se organizam em torno de distintos objetivos, grupos e pressão e temas de interesse”. (UNITED NATIONS. General Assembly Resolution A/53/170, 10.07.1998, p. 02.)

${ }^{20}$ ORTIZ, Renato. Mundialização e Cultura. São Paulo: Brasiliense, 1994. p. 7.
}

Revista de Direito Brasileira | São Paulo, SP | v. 14 | n. 6 | p. 89 - 108 | maio/ago. 2016 
resta de fato prejudicado nesse contexto justamente pelo argumento da falta de um mandato gerado em um processo democrático nas $\mathrm{ONG} \mathrm{s}^{21}$.

Além disso, as votações nas relações internacionais estão confinadas aos sujeitos do direito internacional, destinatários da norma internacional e que têm de aplicar e executar as decisões, ou seja, aos Estados. Nesse caso, a exigência do mandato eletivo pode até não parecer necessária uma vez que governos não democráticos possuem o direito ao voto. Todavia, esse argumento não tem se justificado e as ONG's em sua maior parte reconhecem o seu limite e não reclamam o direito ao voto.

A falta de democracia na escolha de seus representantes, portanto, não remove das ONG's o caráter de emissárias legítimas da sociedade, uma vez que a escolha das problemáticas e ações é em regra feita à luz da aceitação pela opinião pública. Por outro lado, as ONG's são dependentes de financiamentos privados e doadores e caso não obtivessem a aceitação pública dificilmente seriam capazes de sustentar suas atividades.

Enfim, a partir da observação das normas internacionais pertinentes e dos argumentos acadêmicos parece não restar dúvida sobre a legitimidade geral da participação das ONG's na política internacional ambiental. Tal participação se apresenta particularmente justificada e benéfica na medida em que dá voz para as preocupações sociais em processos internacionais. As políticas democráticas ou articulação de interesses nesse contexto não dependem exatamente de um mandato democrático. Além disso, como se poderá observar nos capítulos seguintes, importantes instrumentos internacionais apoiam e promovem uma maior participação das ONG's nos processos internacionais.

\section{ONG'S: CONCEITO, CLASSIFICAÇÃO E FUNÇÕES}

Há uma grande quantidade de instrumentos jurídicos internacionais que se referem às ONG's, para citar alguns no corpo do direito internacional ambiental, o artigo 71 da Carta da ONU, o Capítulo 27 da Agenda 21, o artigo 23 (5) da Convenção de Diversidade Biológica (CDB), o artigo XI (7) da Convenção sobre Comércio Internacional das Espécies da Flora e Fauna Selvagens Ameaçadas de Extinção (CITES), o artigo 7 (6) da Convenção sobre Mudança do Clima (CMC).

À luz das resoluções das Nações Unidas no âmbito do ECOSOC pode-se ter uma visão geral dos elementos que diferem as ONG's de outras instituições internacionais ${ }^{22}$, a saber: (i) ato de fundação, visto que as organizações internacionais são estabelecidas por um acordo intergovernamental, isto é, um instrumento de direito internacional público, as ONG's em contraste são em regra fundadas por indivíduos, grupos ou associações, no âmbito do direito interno dos Estados; (ii) sede e escritório, pois algumas instituições como o ECOSOC exigem que as ONG's tenham uma estrutura organizacional básica, como consequência, algumas formas de grupos não governamentais, que operam sem uma organização formal (tal como redes de ativistas internacionais) não são considerados ONG's no contexto destas instituições; (iii) objetivos e atividades de apoio à cooperação internacional, como por exemplo no âmbito do ECOSOC que requer que as ONG's sejam favoráveis à Carta das Nações Unidas e aos seus objetivos específicos; (iv) representatividade ou especialização, no sentido, segundo o ECOSOC, de representar os principais elementos da opinião pública ou fornecer conhecimentos e

\footnotetext{
${ }^{21}$ Ver, nesse sentido, EDWARDS, Michael. NGO rights and responsibilities: A new deal for global governance. London: The Foreign Policy Centre, 2000.

${ }^{22}$ UNITED NATIONS. ECOSOC. Resolution 288 B(X). 27/02/1950. Review of Consultative Arrangements with Non-Governmental Organizations. (O parágrafo $8^{\circ}$ foi emendado pela UNITED NATIONS. ECOSOC. Resolution 1296 (XLIV). 23/05/1968. Arrangements for Consultation with Non- Governmental Organizations).

UNITED NATIONS. ECOSOC. Resolution 1996/31. 25/07/1996. Consultative relationship between the United Nations and non-governmental organizations. Parte I.
}

Revista de Direito Brasileira | São Paulo, SP | v. 14 | n. 6 | p. 89 - 108 | maio/ago. 2016 
competências específicas para a instituição internacional em questão. (v) não-lucratividade ou financiamento, nesse sentido, o ECOSOC determina que as principais fontes das ONG's credenciadas devem ser derivadas de contribuições de afiliadas nacionais ou membros individuais. Se o financiamento for proveniente de outras fontes (não-membros, governos) a ONG deve explicar ao ECOSOC suas razões para não cumprir os requisitos gerais de financiamento $^{23}$. (vi) ausência de controle governamental sobre suas atividades, uma vez que as ONG's devem ser independentes dos governos em suas atividades e opiniões. O ECOSOC se refere à "livre expressão dos pontos de vista". (vii) governança, tal como os requisitos bastante detalhados exigidos pelo ECOSOC, incluindo-se estrutura democrática, responsabilidade dos representantes, transparência dos procedimentos de tomadas de decisão ${ }^{24}$.

A doutrina sobre o assunto, embora crescente, não é consensual sobre a definição do termo "organização não governamental", especialmente, no campo do direito internacional. Há, no entanto, como visto acima, uma série de elementos que podem ser identificados na definição. A busca por esta conceituação pode ser guiada ao menos por duas considerações relevantes. Em primeiro lugar, a revisão das normas internacionais acima mencionadas permite identificar critérios mínimos. Por exemplo, as ONG's podem ser distinguidas das organizações internacionais. $\mathrm{Ou}$ ainda, o direito internacional pressupõe uma qualificação mínima para que seja tratada como instituição. Ademais, as ONG's devem ser livres para expressar suas opiniões independentemente dos governos. Em segundo lugar, é importante refletir sobre a participação das ONG's na cooperação internacional. Nesse sentido, para os fins deste estudo, o termo ONG pode ser conceituado como organização permanente e democrática, formada por indivíduos ou grupos de indivíduos qualificados em relevantes domínios, que se expressam de maneira independente de seus governos, com estrutura institucional básica operando de forma não lucrativa, pautada pelos objetivos de cooperação internacional.

Com base nos seus objetivos principais, interesses ou motivações, podem ser discernidas as ONG's de interesse privado e interesse público (PINGO's, em inglês), ONG's empresarias e industriais (BINGO's, em inglês) e ONG's ambientais ou de direitos humanos. Ocorre que se a participação das ONG's na governança internacional ambiental destina-se a assegurar os legítimos interesses sociais, o objetivo das organizações não pode ser uma razão para diferenciar os direitos dos participantes. Os objetivos privados podem ser tão legítimos como os públicos. Todavia, é preciso dizer, que nem todos os interesses sociais operam em pé de igualdade e possuem as mesmas chances para contribuir no processo político. Obviamente quem lida com os interesses do comércio e indústria geralmente possui mais possibilidades de recursos a partir das suas atividades habituais do que os que trabalham com interesses públicos. Como consequência, as ONG's de interesse público podem estar sub-representadas. Dessa forma, há motivo para um tratamento diferenciado entre as ONG's com base nos seus objetivos, por exemplo, em relação aos custos para a acreditação ou apoio à participação das ONG’s de interesse público.

Em face do tipo de atividades que promovem, costumam ser diferenciados os grupos de protestos nas ruas dos grupos que se concentram em lobby dentro das arenas políticas. Ou ainda ONG's com opinião profissional e pública. De todo modo, as atividades das ONG's estão sujeitas a constantes mudanças e, portanto, isso não poderia ser um critério de legitimidade ou tratamento diferenciado em seu direito de participação, salvo se houver desvirtuamento do objetivo de cooperação internacional.

\footnotetext{
${ }^{23}$ UNITED NATIONS. ECOSOC. Resolution 1996/31. 25/07/1996. Consultative relationship between the United Nations and non-governmental organizations. Parte I, N.13.

${ }^{24}$ É interessante atentar para este último requisito, a necessidade de exibição de estruturas democráticas. Como dito em capítulo anterior as ONG's não possuem um mandato democrático. Ademais, como se justificaria esta exigência para organizações de interesses privados a fim de quem possam agir legitimamente como membros da sociedade civil? A este respeito, é revelador informar que tal requisito está relacionado às instituições internacionais mais genéricas e não às instituições dos acordos multilaterais ambientais que, de fato, não exibem tais restrições.
}

Revista de Direito Brasileira | São Paulo, SP | v. 14 | n. 6 | p. 89 - 108 | maio/ago. 2016 
No que tange ao âmbito da atividade, o ECOSOC distingue as ONG's que possuem uma finalidade única ou agenda estreita de outras com uma agenda política ampla. As ONG's que solicitam acreditação junto ao ECOSOC são agrupadas em três categorias consultivas ${ }^{25}$. Na categoria $\mathrm{I}^{26}$ encontram-se as de caráter consultivo geral cujo âmbito de trabalho se ocupa da maioria dos temas e atividades do Conselho e dos seus órgãos subsidiários. Na categoria II $^{27}$ estão enquadradas as ONG's com competência especial e se referem especificamente a alguns dos campos de atividades desempenhadas pelo ECOSOC. Na categoria III $^{28}$ outras organizações que não se enquadram no status consultivo geral ou especial, por serem mais técnicas e/ou restritas, mas que o Conselho, ou o Secretário Geral das Nações Unidas após ouvir o Conselho ou o Comitê de Organizações Não Governamentais, considere sua capacidade de fazer contribuições ocasionais e pertinentes para os trabalhos do Conselho ou de seus órgãos subsidiários, podem ser incluídas em uma lista, conhecida como Roster. Todavia, tais distinções em categorias possuem maior significância se aplicadas por instituições internacionais com mandato amplo e não exatamente quando estão envolvidas matérias específicas tal como ocorre na maioria dos acordos multilaterais ambientais.

Em relação aos tipos de membros, pode-se distinguir as organizações pela origem de seus membros, se provenientes de países industrializados ou em desenvolvimento. Esta distinção é importante pois evoca o mais amplo conceito de equilíbrio regional na representação. Igualmente, o objetivo de alcançar um equilíbrio Norte-Sul de ONG's se apresenta particularmente relevante uma vez que o Norte tem um foco maior nas questões ambientais enquanto que o Sul tende a estar mais preocupado com os vínculos entre a degradação ambiental e a pobreza ou com o poder sobre os seus próprios recursos naturais. Não é fácil argumentar a concessão de direitos de participação diferenciados com base na origem de seus membros. Entretanto, como no caso acima referido, entre as ONG's de interesse privado e público, parece bastante plausível o tratamento diferenciado com vistas à representação equilibrada de interesses legítimos.

Quanto à estrutura organizacional, faz-se a distinção entre as ONG's nacionais, com interesses organizados em um país, e as ONG's internacionais, com escritórios em vários países. Não resta clara a razão para se diferir a legitimidade entre elas pelos interesses representados com base na estrutura. Na verdade, no contexto da governança internacional ambiental, a grande maioria das questões abordadas em termos de cooperação são relevantes aos níveis locais e regionais. Nesse sentido, as ONG's nacionais participantes da política internacional ambiental desempenham um papel primordial em trazer o conhecimento e as preocupações locais para $\mathrm{o}$ nível internacional.

As ONG's também podem variar conforme suas fontes de financiamento, por exemplo, se públicos ou privados. BINGO's, em geral, derivam suas finanças de contribuições dos membros. No que diz respeito aos PINGO's, a imagem é mais diversificada, como ocorre com o Greenpeace que deriva a maior parte do seu financiamento de contribuições dos membros e doações. A cultura de doadores é diferente entre países. Nas regiões mais pobres as doações são mais difíceis e por isso as ONG's possuem maiores dificuldades financeiras ${ }^{29}$. A diferenciação entre as ONG's a partir do critério de fontes de financiamento torna-se relevante se estiver em

\footnotetext{
${ }^{25}$ Por ter um status consultivo, por exemplo, é permitido a uma ONG: (i) realizar uma análise especializada de questões diretamente ligadas a sua experiência na área; (ii) funcionar como um agente de alerta rápido; (iii) ajudar a monitorar e aplicar acordos internacionais; (iv) ajudar na conscientização de questões relevantes; (v) promover as metas e objetivos das Nações Unidas; assistir a conferências e contribuir com informação essencial em eventos da organização; (vi) apresentar declarações escritas e orais nesses eventos, etc.

${ }^{26}$ Conforme artigo 22 da Resolução 1996/31 do ECOSOC.

${ }^{27}$ Conforme artigo 23 da Resolução 1996/31 do ECOSOC.

${ }^{28}$ Conforme artigo 24 da Resolução 1996/31 do ECOSOC.

${ }^{29}$ Ver, nesse sentido, HULME, D.; EDWARDS, M. (eds.) NGOs, states and donors: too close for comfort. New York: St. Martin's Press, 1997.
} 
perigo a independência de uma ONG ou a sua legitimidade para tomada de decisão na governança internacional ambiental.

São vários critérios de classificação das ONG's divididos em dimensões, mas que parecem influenciar pouco no que diz respeito aos seus direitos de participação. Alguns podem ser potencialmente relevantes quando se trata de pensar em um tratamento diferenciado das ONG's no âmbito das instituições internacionais. Nesse sentido, a distinção entre pública e privada, entre BINGO's e ONG's ambientais, entre ONG's de países industrializados e em desenvolvimento, parece relevante não do ponto de vista da legitimidade ou direitos de participação, mas sim por abranger a capacidade de participar que varia conforme o grau de recursos financeiros existentes. Com efeito, estes critérios podem servir de suporte para facilitar o acesso à formulação de políticas internacionais ambientais, especialmente a partir de regiões mais pobres, a fim de se minimizar a tendência estrutural de sub-representação de tais interesses.

As ONG's executam uma variedade de funções no âmbito do direito e política internacional. Nesse sentido, é relevante compreender os canais de influência das ONG's a fim de cumprir suas funções na governança internacional ambiental. As políticas internacionais ambientais e consequentemente o direito internacional ambiental se caracteriza por incertezas. Nelas podem ser incluídas desde as incertezas científicas sobre as causas e efeitos de um problema ambiental, as respostas estratégicas a tais questões e as incertezas jurídicas sobre os meios disponíveis para alcançar os objetivos da política desejada.

A incerteza também pode incidir sobre os efeitos dos comportamentos de atores subnacionais, tal como a indústria e os consumidores, e ainda sobre a própria eficácia da aplicação das normas internacionais quando por estas forem adotadas. Nesse sentido, muito embora o princípio da precaução ofereça a base para se tomar medidas na ausência de completa certeza científica, a incerteza se configura em muitos casos como um fator importante que dificulta a adoção de medidas eficazes.

Nesse contexto, as ONG's desempenham um papel fundamental na abordagem das incertezas, pois podem melhorar a base de conhecimento para a governança internacional ambiental ao reunir e divulgar informações relevantes às autoridades políticas e normativas e ao público em geral. Servem de exemplos pela atuação a este respeito o World Resources Institute ${ }^{30}$, o World Watch Institute ${ }^{31}$, o World Conservation Monitoring Centre ${ }^{32}$, a IUCN's Environmental Law Centre ${ }^{33}$, a International Institute for Sustainable Development (IISD) ${ }^{34}$ e a Foundation for International e Environmental Law and Development (FIELD) ${ }^{35}$. Um exemplo de atuação reconhecido oficialmente é o da $\mathrm{TRAFFIC}^{36}$ que tem fornecido informações relevantes às Partes no regime internacional da CITES sobre o comércio ilegal e espécies ameaçadas de extinção.

$\mathrm{Na}$ prática, as ONG's notavelmente contribuem para melhorar a base de conhecimentos por meio da organização de materiais de informação e eventos paralelos na oportunidade das conferências internacionais ambientais. Suas atividades são reconhecidas como canais de influência pelo direito internacional, quer formalmente pelas regras de procedimento de tais conferências, quer informalmente por meio das práticas das ONG's, como na organização de workshops, seminários e outras formas de reunião independentes.

Além do fornecimento de informações, as ONG's influenciam diretamente no processo de decisão política internacional por meio de lobbies e advocacia. A advocacia se refere aqui à atuação pública enquanto defensores de suas causas com base em posicionamentos formais

\footnotetext{
${ }^{30}$ Ver, nesse sentido, <http://www.wri.org/>

${ }^{31}$ Ver, nesse sentido, <http://www.worldwatch.org/>

${ }^{32} \mathrm{Ver}$, nesse sentido, <http://www.unep-wcmc.org/>

${ }^{33}$ Ver, nesse sentido, <http://www.iucn.org/themes/law/elp_elc.html>

${ }^{34}$ Ver, nesse sentido, <http://iisd1.iisd.ca/>

${ }^{35}$ Ver, nesse sentido, <http://www.field.org.uk/>

${ }^{36}$ Ver, nesse sentido, <http://www.traffic.org>
} 
acordados dentro da instituição. Os lobbies acontecem nos corredores dos encontros internacionais em que representantes dos governos dialogam com representantes das ONG's. Os eventos paralelos às conferências internacionais geram opções de pautas de negociação que podem ser tomadas pelos delegados. Oportunidades formais também são oferecidas às ONG's por muitas instituições internacionais. Nestas se incluem reuniões oficiais com elaboração de declarações escritas que são por sua vez refletidas nas normas jurídicas.

As ONG's também podem ser recrutadas como assessoras diretas dos governos, por vezes até atuando como negociadoras. Um exemplo disso é a assistência prestada pela Aliança de Pequenos Estados Insulares (AOSIS, em inglês) nas negociações internacionais sobre o clima. Seus representantes com frequência negociam em nome dos representantes dos governos. No entanto, esta estreita cooperação pode ensejar uma atuação das ONG's sob as instruções do governo e não propriamente de acordo com as pautas legítimas adotadas por elas.

Cada vez mais as ONG's têm desempenhado um papel ativo na avaliação e implementação das políticas ambientais. A maior parte dos mecanismos de solução de controvérsias internacionais são de caráter intergovernamental e, portanto, não permitem a participação de atores não-estatais. Como exceção pode-se citar o Tribunal Internacional sobre o Direito do Mar (ITLOS, em inglês) ${ }^{37}$. As ONG's podem desempenhar uma função na qualidade de amicus curiae nas disputas internacionais e adicionar informações aos $\operatorname{casos}^{38}$.

Em diversos mecanismos de cumprimento dos acordos multilaterais ambientais, as ONG's podem fornecer informações sobre um caso ou até mesmo indiretamente contribuir para desencadear as disputas mediante a apresentação de informações relevantes aos atores com competência para ingressar com o processo. A possibilidade de adicionar informações sobre a implementação dos compromissos internacionais é de particular relevância, dado que a maioria dos acordos internacionais ambientais dependem dos relatórios das Partes sobre os seus esforços na implementação e os governos por óbvio são relutantes em denunciar seus próprios atrasos no cumprimento. Com efeito, os dados compilados pelas ONG's podem proporcionar uma fonte valiosa e independente de informações em face dos relatórios nacionais.

A transparência dos processos políticos é um dos pilares fundamentais da governança democrática ambiental. É um dos pré-requisitos para que as decisões políticas possam ser avaliadas pelo público em geral. De outro lado, a garantia da transparência na tomada da política internacional constitui um enorme desafio em especial pelo fato de que frequentemente as negociações intergovernamentais são realizadas a portas fechadas. Nesse cenário, as ONG's desempenham um papel crucial no aumento da transparência dos processos políticos internacionais no sentido de garantir que as autoridades possam responsabilizadas pelas decisões políticas. As ONG's elaboram relatórios das negociações internacionais revelando o comportamento por parte dos governos. Esses documentos não apenas contribuem para informar um público mais amplo, mas também fornecem uma visão importante e abrangente aos próprios delegados individuais que são parte nas negociações e, ainda, expõem e envergonham governos pelo seu inapropriado comportamento nas negociações internacionais

Outra função relevante das ONG's é o apoio às secretarias das instituições internacionais. Como mencionado acima, as Partes na CITES conferiram as funções de controle sobre o comércio internacional de espécies ameaçadas de extinção a uma rede internacional de ONG's (TRAFFIC) e a organização não governamental World Conservation Monitoring Centre

\footnotetext{
${ }^{37}$ Ver, nesse sentido, <https://www.itlos.org/en/top/home>

${ }^{38}$ Ver, nesse sentido, "In the matter of an arbitration under annex vii to the United Nations Convention on the Law of the Sea (1982)". The "Arctic Sunrise" (Pca Case No 2014-02). The Kingdom of the Netherlands Versus The Russian Federation. Disponível em: <http://www.greenpeace.org/international/Global/international/briefings/climate/2014/ITLOS-amicus-curiae-brief15092014.pdf>
} 
que administra o banco de dados da secretaria sobre as transações do comércio internacional de espécies ameaçadas regulado pela CITES $^{39}$.

Pode-se tirar como conclusão por intermédio desta breve demonstração das funções das ONG's é que de fato há uma serie de atividades e canais de influência. Certas funções estão intimamente relacionadas como a prestação de informações e a política de defesa da causa. As funções desempenhadas pelas ONG's na governança internacional ambiental estão parcialmente refletidas nas normas internacionais em vigor. Há regras estabelecidas pelas instituições internacionais que, apesar de não uniformes, permitem a distribuição de material de informação, organização de eventos paralelos, participação formal em algumas reuniões intergovernamentais e alguma atuação na revisão e aplicação das normas internacionais ambientais. Todavia, as atividades e influência as ONG's vão muito além destas.

\section{PARTICIPAÇÃO DAS ONG'S NOS ACORDOS MULTILATERAIS AMBIENTAIS (AMA'S): UMA ANÁLISE DA CITES}

A participação das ONG's na formulação das políticas internacionais ambientais pode ser analisada no âmbito dos acordos multilaterais ambientais (AMA's). Muito embora esta participação na formulação de políticas incida após a entrada em vigor dos tratados é possível identificá-la eventualmente no estágio de sua formação.

Para além das disposições específicas abordadas abaixo a respeito da acreditação das ONGs, acesso a reuniões, entre outras, as referências gerais às ONG's nos textos dos acordos multilaterais ambientais refletem o crescente reconhecimento do papel das ONG's na governança internacional ambiental. Desse modo, em contraste com os acordos multilaterais ambientais precursores, tal qual o Tratado da Antártida de 1959 e a Convenção Internacional Baleeira de 1946, os acordos formalizados após a Conferência do Rio sobre Meio Ambiente e Desenvolvimento de 1992 contêm referências específicas sobre as ONG's ${ }^{40}$. Nesse particular, a maior parte dos acordos pós-Rio exige explicitamente, na linguagem padronizada, que a Conferência das Partes (COP's) busque e se utilize, quando apropriado, dos serviços, cooperação e informações fornecidas por organizações internacionais competentes e órgãos intergovernamentais e não governamentais ${ }^{41}$. Isso é representativo da tendência de crescente reconhecimento do papel das ONG's na governança internacional ambiental.

A Convenção sobre o Comércio Internacional de Espécies da Flora e Fauna Selvagens Ameaçadas de Extinção (CITES) foi adotada em 1973 tornando-se um dos primeiros modernos regimes jurídicos internacionais sobre meio ambiente ${ }^{42}$. Esse instrumento abriu novos caminhos para a proteção da vida selvagem tendo em vista que seu foco não recai diretamente sobre a conservação das espécies ou habitats, mas sim abrange uma atividade humana específica que pode afetar a conservação de espécies, qual seja, o comércio internacional.

O objetivo primordial da CITES é impedir a exploração excessiva das espécies nela enumeradas ocasionada pelo comércio internacional. Desse modo, emprega controles sobre o mercado de modo a eliminar as ameaças às espécies em vias de extinção. Nesse passo, a Convenção estabelece três Anexos, os quais classificam as espécies de acordo com o impacto do comércio sobre o seu estado de conservação.

\footnotetext{
${ }^{39}$ Ver, nesse sentido, <http://www.unep-wcmc.org/>

${ }^{40}$ Conforme preâmbulos da Convenção sobre Diversidade Biológica e Convenção para o Combate da Desertificação; artigo $4^{\circ}$ (1) (i) da Convenção sobre Mudança do Clima; artigo 3 (7) da Convenção de Aarhus.

${ }^{41}$ Conforme artigo 7 (2) (1) da Convenção sobre Mudança do Clima; artigo 13 (4) (i) do Protocolo de Quioto; artigo 29 (4) (c) do Protocolo de Cartagena; artigo 22 (2) (h) da Convenção para o Combate da Desertificação.

${ }^{42}$ No Brasil, entrou em vigor em 1975, sendo promulgada pelo Decreto n. 76.623, de 17/11/1975.
} 
As espécies listadas no Anexo I são as mais ameaçadas e, portanto, seu comércio é altamente restrito $^{43}$. Tratam-se de espécies ameaçadas de extinção e a CITES proíbe o seu comércio internacional, exceto quando o propósito da importação não é comercial $^{44}$, por exemplo, para investigação científica. Nesses casos excepcionais, o comércio pode acontecer desde que autorizado, por meio de concessão de uma licença de importação e de uma licença de exportação $^{45}$. No Anexo II são enumeradas as espécies que não estão necessariamente ameaçadas de extinção, mas que podem se tornar, a menos que o seu comércio seja rigorosamente controlado. Dessa maneira, o comércio internacional de espécies do Anexo II pode ser autorizado pela concessão de uma licença de exportação. Não há necessidade de licença de importação para estas espécies. Cumpre acrescer que as licenças ou certificados só devem ser concedidos se as autoridades competentes considerarem que determinadas condições foram atendidas, sobretudo, que o comércio não será prejudicial para a sobrevivência das espécies na natureza $^{46}$. O Anexo III traz uma lista de espécies incluídas a pedido individual das Partes no regime da Convenção, que almejam a cooperação internacional de outros países para que seja impedida a sua exploração insustentável ou ilegal ${ }^{47}$. O comércio internacional de exemplares de espécies incluídas no Anexo III é permitido mediante a apresentação das licenças ou certificados $\operatorname{apropriados}^{48}$.

As espécies podem ser adicionadas, removidas e transferidas entre os Anexos I e II por decisão da Conferência das Partes, em suas reuniões ordinárias ${ }^{49}$. Mas as espécies podem ser adicionadas ou removidas do Anexo III a qualquer momento e por qualquer Parte unilateralmente, embora a Conferência das Partes recomende que as alterações sejam programadas para coincidir com as alterações aos Anexos I e II.

Há cerca de 800 espécies animais e vegetais listadas no Anexo I e quase 35.000 espécies estão no Anexo II. Enquanto a maioria das Partes se encontram vinculadas por estas listas, uma Parte pode, no entanto, formular reservas a espécies específicas quando se torna Parte da CITES ou no momento em que a espécie é listada. Uma Parte quando formula uma tal reserva é fica isenta da obrigação no que diz respeito ao comércio daquela espécie ${ }^{50}$.

A CITES contém várias instituições sobre as quais importa a compreensão, uma vez que o nível de participação das ONG's se distingue de acordo com a instituição em questão. Desse modo, a Convenção estabelece uma Conferência das Partes (COP) como principal órgão regulador. Além disso, estabelece um secretariado que realiza um conjunto de funções, dentre tais, estudos técnicos e científicos, sobre os relatórios das Partes a partir dos quais solicita mais informações para assegurar a aplicação da Convenção, e ainda faz recomendações para a implementação da Convenção. Na prática, a Secretaria é um importante canal para o envolvimento das ONG's, por exemplo, por intermédio de projetos em conjunto ou prestação de informações em reuniões com as ONG's que podem ser usadas para influenciar as decisões das Partes.

A Conferência das Partes (COP), por sua vez, criou várias comissões ${ }^{51}$. A mais relevante é a Comissão Permanente da Conferência das Partes que é o órgão responsável pela execução da política geral e coordenação das outras comissões. Além desta, há uma Comissão para os Animais e outra Comissão para as Plantas, as quais possuem natureza técnica e dentre suas

\footnotetext{
${ }^{43}$ Conforme artigo II (1) da Convenção.

${ }^{44}$ Conforme artigo III da Convenção.

$45 \mathrm{O}$ artigo VII da Convenção prevê uma série de isenções a essa proibição geral.

${ }^{46}$ Conforme artigo IV da Convenção.

${ }^{47}$ Conforme artigo II (3) da Convenção).

${ }^{48}$ Conforme artigo $\mathrm{V}$ da Convenção.

${ }^{49}$ Conforme artigo XV da Convenção.

${ }^{50}$ Conforme artigos XV, XVI e XXIII da Convenção.

${ }^{51}$ CITES. Resolution Conf. 11.1 on Establishment of Committees, 11th meeting of the Conference of the Parties Gigiri (Kenya), 2000.
} 
funções estão o aconselhamento e orientação à Conferência das Partes, outras comissões e a Secretaria.

O regime internacional estabelecido pela CITES é considerado entre os mais modernos e liberais dentre os tratados ambientais em termos de participação das ONG's, sendo que algumas de suas disposições sobre participação foram reproduzidas em outros tratados ambientais. Em parte, isso pode ser explicado pelas origens da Convenção, já que a ideia de um acordo internacional para controlar o comércio da vida selvagem foi iniciada pelo no setor não governamental, mais especificamente por uma Resolução de 1963 da IUCN ${ }^{52}$.

Um alto nível de participação das ONG's na CITES é amplamente visto como um elemento necessário para o sucesso global da Convenção ${ }^{53}$. As ONG's muitas vezes podem trazer uma experiência necessária para as deliberações e, em particular, sobre as questões pertinentes as listas de espécies, as ONG's podem estar mais bem informadas do que os próprios delegados das Partes. Além disso, as ONG's desempenham um papel reconhecido na implementação da Convenção. Este papel tem caráter informal, quando muitas outras formas de organização para vida selvagem cooperam estreitamente com ONG's, bem como formal, quando várias resoluções e decisões citam especificamente algumas ONG's como parceiras na implementação da Convenção.

Ao contrário de outros tratados multilaterais ambientais, as ONG's ativas na CITES são principalmente de interesse público (PINGO's). Isso pode ser explicado pelo fato de que a maioria das espécies relacionadas nos Anexos da CITES não possuem significativo valor comercial. No entanto, isso não quer dizer que as ONG's tendem a falar a uma só voz. Em vez disso, há uma divisão clara entre as ONG's que favorecem os direitos dos animais e aquelas que melhor aceitam o conceito de uso sustentável e valor econômico das espécies. Os debates refletem a divisão, embora não formal, entre os países desenvolvidos e em desenvolvimento, sendo certo que muitas das ONG's a favor dos direitos dos animais procedem do mundo desenvolvido.

\subsection{ACREDITAÇÃO E ACESSO ÀS REUNIÕES}

Independentemente das diferenças ocasionais na referência às ONG's nos acordos multilaterais ambientais (AMA's), é certo que em todos os regimes internacionais ambientais está prevista a oportunidade geral das ONG's alcançarem o status de observador nas reuniões de seus órgãos gerais. Nesse sentido, uma vez que a Convenção de Viena de 1985 prevê no seu artigo 6 (5) que "Qualquer órgão ou departamento, tanto nacional como internacional, governamental ou não", que seja "qualificado" em áreas relevantes, tenha "informado o secretariado seu desejo de estar representado num encontro da Conferência das Partes como observador, pode ser admitido, a não ser que um terço das Partes coloque objeções", esta norma se tornou uma fórmula relevante ${ }^{54}$.

\footnotetext{
${ }^{52}$ IUCN - World Conservation Union é um organismo internacional composto pelos Estados, agências do governo e organizações não governamentais. A IUCN, então, elaborou os primeiros esboços da Convenção uma vez que estava intimamente envolvida em todo o processo de negociação. Com efeito, por um tempo, o secretariado da CITES foi alojado na IUCN.

${ }^{53}$ O nível de participação das ONG's na CITES veio a aumentar ao longo do tempo, o que pode refletir positivamente na confiança sobre a sua capacidade de influenciar o processo. Na COP 11, 160 ONG's foram credenciados; 47 eram ONG's internacionais, e 113 ONG's nacionais.

${ }^{54}$ Conforme artigo 6 (5) da Convenção de Viena; artigo 11 (5) do Protocolo de Montreal; artigo 15 (6) da Convenção da Basileia; artigo 22 (7) da Convenção para o Combate da Desertificação; artigo 23 (5) da Convenção sobre Diversidade Biológica; artigo 29 (8) do Protocolo de Cartagena; artigo 7 (6) da Convenção sobre Mudanças Climáticas; artigo 13 (8) do Protocolo de Quioto; regra 7 (1) das regras de procedimento de 1999 para a Convenção de Ramsar. Ver ainda RAUSTIALA, Kal. The Participatory Revolution in International Environmental Law. In: Harvard Environmental Law Review, Vol. 21, 1997. p. 543.
}

Revista de Direito Brasileira | São Paulo, SP | v. 14 | n. 6 | p. 89 - 108 | maio/ago. 2016 
A fórmula padrão estabelece uma dupla condição para o credenciamento de ONG's. Em primeiro lugar, uma ONG deve ser "qualificada" no objeto regulado pela Convenção ou como descrito em algumas convenções deve apresentar "competência nas matérias abrangidas pela Convenção". Em segundo lugar, a acreditação não deve receber objeções de um terço ou mais dos Estados-membros. Além disso, o uso da palavra "pode" indica que a decisão final acerca da participação permanece a critério dos Estados. E, finalmente, convém salientar que a fórmula padrão estabelecida não limita sua aplicação a qualquer tipo de $\mathrm{ONG}$, mas se refere, por exemplo, a ambas as organizações ambientais e empresariais.

As disposições da CITES, bem como as regras de procedimento e decisões da COP, regulamentam a acreditação das ONG's para participarem das reuniões nas Conferências das Partes. Como resultado de discussões na COP-10, em que a participação das ONG's foi notada como reduzida em questões controversas, o tema da participação das ONG's esteve elevado nos debates até a COP-11, quando o processo foi regulamentado e várias decisões sobre o assunto foram adotadas. ${ }^{55}$

De acordo com o artigo XI (7) da CITES: "Qualquer organismo ou entidade tecnicamente qualificado na proteção, preservação ou administração da fauna e flora selvagens e que esteja compreendido em qualquer das categorias mencionadas a seguir, poderá comunicar à secretaria seu desejo de estar representado por um observador nas reuniões da conferência e será admitido, salvo objeção de pelo menos um terço das partes presentes: a) organismos ou entidades internacionais, tanto governamentais como não governamentais, assim como organismos ou entidades governamentais nacionais, e b) organismos ou entidades nacionais não governamentais que tenham sido para tal autorizados pelo Estado onde se encontrem localizados. Uma vez admitidos, estes observadores terão o direito de participar sem direito a voto nos trabalhos da reunião".

Em contraponto com a fórmula padrão, o artigo XI (7) da CITES determina que os organismos e agências "tecnicamente qualificados" serão admitidos, salvo objeção de um terço das Partes presentes. A exigência da "qualificação técnica" usada pela CITES é mais restritiva do que apenas o termo "qualificado" utilizado na fórmula padrão. Outro ponto a ser destacado na CITES é a abertura para ONG's nacionais, vista com desconfiança na década de 1970, uma vez que exige autorização dos Estados onde tais ONG's se localizam. Além disso, na $12^{\text {a }}$ Conferência das Partes da CITES em 2002 foi acordado que uma ONG internacional será registrada se demonstrar: (a) "qualificação em proteção, conservação ou manejo da fauna e flora selvagens", e (b) que é uma "organização com personalidade jurídica e caráter internacional em seu mandato e programa de atividades" $" 56$.

No regime jurídico da CITES, para serem acreditadas, as ONG's não apenas devem satisfazer os critérios ${ }^{57}$, mas também são obrigadas a pagar uma taxa ${ }^{58}$. Esta pode ser reduzida em casos individuais, o que na prática é observado em relação às ONG's nacionais dos países em desenvolvimento, mas não há um mecanismo formal estabelecido para esses casos.

No que tange ao acesso às reuniões, a grande maioria dos acordos multilaterais ambientais determina por meio das suas regras de procedimentos que a secretaria notificará as organizações e agências dos encontros das COP's ${ }^{59}$. Uma ONG que deseja participar de uma

\footnotetext{
${ }^{55}$ CITES Doc 11.16, Eleventh Meeting of the Conference of the Parties in Gigiri (Kenya), 2000. Strategic and administrative matters, "Recognition of the Important Contribution made by Observers to the CITES process at Meetings of the Conference of the Parties".

${ }^{56}$ Ver, nesse sentido, a decisão 11.125 no documento CITES. Decisions of the Conference of the Parties to CITES in effect after the 12th meeting.

${ }^{57} \mathrm{Na}$ prática, a Secretaria exerce considerável influência sobre essas determinações. Por exemplo, na COP-11, o Japão se opôs à acreditação do Greenpeace, mas depois de o secretariado indicar que a referida ONG internacional preenchia os critérios para o credenciamento, o plenário aprovou a acreditação.

${ }^{58}$ CITES. Resolution Conf. 10.2, Permits and certificates.

${ }^{59}$ Conforme regra 7 (1) das regras de procedimentos da Convenção de Diversidade Biológica, in verbis: "The Revista de Direito Brasileira | São Paulo, SP | v. 14 | n. 6 | p. 89 - 108 | maio/ago. 2016
} 
reunião tem que estar previamente registrada na secretaria ${ }^{60}$. O registro, por sua vez, confere uma legítima expectativa, mas não o direito, de estar presente nas reuniões.

Vários tipos de reuniões (plenária, comissões, grupos de trabalho, entre outras) acontecem na Conferência das Partes da CITES. Nesse sentido, de acordo com a decisão 11.127, o secretariado e o país anfitrião devem se esforçar para assegurar que a cada observador credenciado seja concedido assento nas sessões da plenária e comissões, a menos que um terço dos representantes das Partes apresentem objeção.

As regras de procedimentos da CITES adotadas em 2000 diferem da maioria dos outros acordos multilaterais ambientais ao regular com mais detalhe o acesso a reuniões de suas comissões subsidiárias. É garantido o direito dos observadores nas sessões plenárias de algumas comissões, inclusive na comissão de orçamento, salvo se um terço das Partes presentes fizerem objeções em votação $^{61}$. Nas comissões de animais e plantas, que reveem o status do comércio de espécies e propõe emendas aos Anexos, as reuniões são em regra abertas apenas aos observadores convidados pelo Presidente da comissão ${ }^{62}$. Além disso, em tais comissões, há possibilidade de adesão de instituições a título pessoal. Ocasionalmente e na prática os membros destas comissões podem vir das $\mathrm{ONG}$ 's que terão direito à voto nas reuniões. Conforme a decisão 11.7 as propostas de candidatos como representantes devem ser apoiadas pelas Partes. Além disso, ideal que os candidatos devem estar associados a uma entidade científica, ter um conhecimento adequado da CITES e receber apoio institucional suficiente para realizar suas funções. Isso sugere que as ONG's devem persuadir as Partes evidenciando sua competência.

Os acordos multilaterais ambientais em geral, e a CITES não configura uma exceção, não regulam o acesso das ONG's às reuniões informais, onde os acordos políticos são frequentemente negociados e as decisões tomadas. A exceção a esta regra pode ser encontrada no regime da Convenção sobre Mudanças Climáticas, em que na COP-4 Buenos Aires, em 1998, decidiu-se permitir que observadores, sem direito à intervenção, participem destas reuniões, a menos que um terço das Partes presentes crie objeções ${ }^{63}$.

\subsection{PARTICIPAÇÃO ATIVA NAS REUNIÕES}

Em termos gerais, as ONG's podem participar sem direito à voto nas deliberações de qualquer reunião sobre matérias que tenham interesse direto, a menos que pelo menos um terço das Partes presentes criem objeções ${ }^{64}$. O nível e a qualidade da participação ficam a critério do Presidente da reunião que pode conceder direitos de participação aos observadores, com exceção do direito à voto e se não houver restrições pelas Partes. A atuação do Presidente é explicitada com respeito às declarações orais previstas nas Conferências das Partes na maioria dos acordos multilaterais ambientais. Nesse sentido, a maior parte dos acordos multilaterais ambientais prevê que ninguém pode fazer o uso da palavra em uma sessão da Conferência das Partes sem prévia

\footnotetext{
Secretariat shall notify any body or agency, whether governmental or non-governmental, qualified in fields relating to the conservation and sustainable use of biological diversity, which has informed the Secretariat of its wish to be represented, of meetings of the Conference of the Parties so that they may be represented as observers unless at least one third of the Parties present at the meeting object." (No mesmo sentido, as regras de procedimentos da Convenção sobre o Combate à Desertificação, a Convenção sobre Mudanças Climáticas, a Convenção da Basileia, Convenção de Viena e seu Protocolo de Montreal e a Convenção de Ramsar.)

${ }^{60}$ Conforme regra 7 (2) das regras de procedimentos da Convenção de Ramsar; regra 3.4 das regras de procedimentos da CITES.

${ }^{61}$ Conforme regra 2 (2) das regras de procedimentos da CITES.

${ }^{62}$ Conforme regra 12 (2) das regras de procedimentos da CITES e regra 5 das regras de procedimentos da CITES para as comissões de animais e plantas.

${ }^{63}$ Conforme Decisão 18/CP.4, na Convenção sobre Mudanças Climáticas.

${ }^{64}$ Conforme regra 7 (2) das regras de procedimentos da Convenção sobre Diversidade Biológica; regra 2 (2) das regras de procedimentos da CITES COP.
}

Revista de Direito Brasileira | São Paulo, SP | v. 14 | n. 6 | p. 89 - 108 | maio/ago. 2016 
autorização do Presidente ${ }^{65}$. Obviamente, as Partes também podem se opor às intervenções dos observadores como dito acima.

No regime jurídico da CITES, a regra é clara no sentido de que não é concedido o direito à voto, ou seja, nenhum observador credenciado poderá votar. Todavia, deve-se notar que as ONG's que não forem acreditadas formalmente como observadores podem ainda participar da reunião como visitantes, porém, sem direito à voz e voto.

Em algumas ocasiões, regras mais específicas foram aprovadas. $\mathrm{Na}$ CITES, diferentemente de outros acordos, foram estabelecidas regras de hierarquia para se proferir declarações. A prioridade é dada aos delegados seguida pelos Estados-membros que não são Partes no regime, organizações intergovernamentais e, por fim, às $\mathrm{ONG}^{\prime} \mathrm{s}^{66}$. Interessante notar no regime da Convenção de Ramsar a previsão de que propostas feitas por observadores possam ser colocadas em votação se endossadas por alguma das Partes ${ }^{67}$. Isso explicita uma certa possibilidade de livre intervenção na deliberação.

Há várias disposições legais em vigor que permitem às ONG's fazer intervenções em reuniões, mas ao mesmo tempo proporcionam certa margem de manobra para o Presidente da Mesa. Com efeito, a decisão 11.70 da COP na CITES afirma que a mesa diretiva em plenária deve se esforçar para permitir aos observadores a intervenção nas reuniões. Como já mencionado, a ordem dos observadores oradores a ser seguida nas reuniões deve dar prioridade aos Estados que não são Partes na CITES, seguidos pelas organizações intergovernamentais e pelas ONG's. Além disso, a decisão 11.71 prossegue no sentido de que o reconhecimento do limite de tempo para completar a pauta da reunião é uma preocupação válida, e os observadores devem ser advertidos a não serem redundantes sobre uma determinada questão. Desse modo, o Presidente da Mesa pode impor limites de tempo às falas e ainda restringir o número de vezes que uma organização pode se manifestar.

\subsection{APRESENTAÇÃO, DISTRIBUIÇÃO DE DOCUMENTOS E DISSEMINAÇÃO DE INFORMAÇÃO}

As ONG's não possuem direitos formais de apresentar documentos, o que ensejaria uma obrigação processual de considerar o seu conteúdo. No entanto, alguns regimes jurídicos contêm regras explícitas que permitem a apresentação de documentos informativos aos delegados, bem como sua distribuição pelas secretarias. As regras de procedimentos da Convenção de Ramsar, por exemplo, permitem à secretaria decidir se documentos apresentados por observadores podem se tornar oficiais. No entanto, em caso de dúvida, deve-se solicitar a opinião da comissão ${ }^{68}$.

A CITES novamente constitui um caso especial desde a adoção no ano de 2000 das suas regras de procedimento. Nesse regime, as ONG's podem apresentar formalmente "documentos informativos" se o observador for claramente neles identificado ${ }^{69}$. De outro lado, cumpre esclarecer que a distribuição informal de material e a organização de eventos paralelos estão fora do âmbito de regulação dos acordos multilaterais ambientais.

Dado o grande número de ONG's que participam das COP's na CITES não é surpreendente a grande quantidade de documentos distribuídos por tais organizações aos

\footnotetext{
${ }^{65}$ Conforme regra 31 das regras de procedimentos da Convenção de Diversidade Biológica; regra 38 das regras de procedimentos da Convenção para o Combate da Desertificação; regra 21 das regras de procedimentos da Convenção de Viena e seu Protocolo de Montreal; regra 21 das regras de procedimento da Convenção de Ramsar.

${ }^{66}$ Conforme regra 17 (1) das regras de procedimentos da CITES COP e recente revisão em 2000 com a CITES Doc.

11.1 (Rev. 1), (2) (c).

${ }^{67}$ Conforme regra 7 (4) das regras de procedimentos para COP da Convenção de Ramsar.

${ }^{68}$ Conforme regra 54 (4) e (5) das regras de procedimentos da Convenção de Ramsar.

${ }^{69}$ Conforme regra 28 das regras de procedimentos para CITES COP e sua revisão em 2000 com a CITES Doc. 11.1 (Rev. 1), (2) (d) (e); regra 15 das regras de procedimentos da CITES para as comissões de animais e plantas.
}

Revista de Direito Brasileira | São Paulo, SP | v. 14 | n. 6 | p. 89 - 108 | maio/ago. 2016 
delegados. A distribuição desta documentação tem sido objeto de debates uma vez que as ONG's desempenham uma contribuição de perícia técnica. Na CITES as regras de procedimento são liberais no sentido de permitir a distribuição da documentação. Nesse sentido, a regra 28.1 prevê que documentos informativos em relação à conservação e utilização de recursos naturais podem ser apresentados por qualquer observador. O único requisito formal aparece na regra 28.2 que determina que todos os documentos devem definir claramente os observadores que os apresentam.

Enquanto as secretarias possuem alguma discricionariedade para considerar as informações oferecidas pelas ONG's, há também algumas regras explícitas nos acordos multilaterais ambientais a serem obedecidas. Por exemplo, de acordo com o artigo 16 (1) (b) da Convenção da Basileia é uma das funções da secretaria preparar e transmitir relatórios baseados, conforme o caso, nas informações fornecidas pelas entidades intergovernamentais ou não governamentais. No regime da Convenção sobre Desertificação, a COP-1 na sua decisão 11 de 1997 previu que o secretariado deve compilar os resumos dos relatórios apresentados pelas Partes bem como informações fornecidas pelos organismos das Nações Unidas, organizações intergovernamentais e ONG's. Por fim, o secretariado do Protocolo de Montreal pode dar início ao procedimento de não cumprimento do Protocolo se entender que há uma possível desconformidade com as normas do regime. Tal fato pode ser compreendido por intermédio das informações fornecidas pelas $\mathrm{ONG}{ }^{70}{ }^{70}$.

No regime jurídico da CITES, basicamente, existem duas formas de distribuição de documentos pelas ONG's. Em primeiro lugar, pode-se apresentar a documentação ao secretariado para que este em seguida a repasse diretamente aos delegados. A decisão 11.128 estabelece que o secretariado deve envidar todos os esforços para assegurar que o informativo sobre a conservação e utilização dos recursos naturais, preparado pelos observadores e aprovado pelo secretariado, seja distribuído em uma reunião da Conferência das Partes aos participantes. A segunda forma de distribuição de documentos ocorre fora das salas de reunião. Nesse caso, a secretaria não desempenha nenhuma função de aprovação prévia de documentos, embora a regra 28.4 autorize qualquer Parte a reclamar em caso de considerar o material ofensivo. As divergências de opiniões precisam ser analisadas e ponderadas nesse contexto para que as ONG's não sejam injustificadamente limitadas no seu direito de participação.

\section{CONCLUSÃO}

É inegável a importância alcançada pela sociedade civil na política internacional do meio ambiente, diante da qual as ONG's são atores que se tornaram cada vez mais influentes ao longo das duas últimas décadas do século XX. Todavia, no processo de democratização da elaboração e implementação das políticas internacionais ambientais pode-se afirmar, a partir das regras e práticas estabelecidas em várias instituições internacionais, que o papel das ONG's ainda está em evolução.

Nesse sentido, a pesquisa revela que, em muitos aspectos, as ONG's têm tido consideráveis oportunidades e direitos de participação, tal como ocorre notadamente na grande maioria dos regimes multilaterais ambientais. Em geral, a participação das ONG's pode ser observada pelas Partes como uma fonte de energia e força para realização dos objetivos das

\footnotetext{
${ }^{70}$ Non-compliance procedure (1998), (3), in verbis: "Where the Secretariat, during the course of preparing its report, becomes aware of possible non-compliance by any Party with its obligations under the Protocol, it may request the Party concerned to furnish necessary information about the matter. If there is no response from the Party concerned within three months of such longer period as the circumstances of the matter may require of the matter is not resolved through administrative action or through diplomatic contacts, the Secretariat shall include the matter in its report to the Meeting of the Parties pursuant to Article 12 (c) of the Protocol and inform the Implementation Committee, which shall consider the matter as soon as practicable".
}

Revista de Direito Brasileira | São Paulo, SP | v. 14 | n. 6 | p. 89 - 108 | maio/ago. 2016 
Convenções. Contudo, alguns pontos ainda podem ser levantados a fim de se discutir o aperfeiçoamento da participação das ONG's nos regimes ambientais notadamente em face da maior aproximação deste estudo com o regime jurídico da CITES.

Em primeiro lugar, a Comissão Permanente da CITES poderia ser mais aberta à participação das ONG's, por se tratar de um órgão que toma decisões importantes acerca dos direcionamentos políticos da CITES, bem como sua implementação. As ONG's ainda não adquiriram a oportunidade de influenciar no processo de negociação dessa Comissão que permanece em salas fechadas, o que parece contraditório com o espírito da CITES e prática nas Conferências das Partes e nas Comissões de Animais e Plantas. Além disso, as ONG's já comprovaram sua capacidade de cooperar com o regime jurídico estabelecido. Com efeito, para superar esse obstáculo poderiam ser desenvolvidas regras de procedimentos para intervenção das ONG's, inclusive poder-se-ia continuar com a possibilidade de sessões fechadas, mas apenas se a maioria das Partes no regime acordassem nesse sentido.

Em segundo lugar, é possível repensar o papel da secretaria na filtragem dos documentos apresentados pelas ONG's, exceto para garantir que tais documentos cumpram o requisito da autoria identificável. Tendo em vista a possibilidade de questionamento pelas Partes em caso de ofensa, não parece necessário sobrecarregar a secretaria com a análise prévia de uma enorme quantidade de documentos apresentados pelas ONG's. Nesse sentido, a função de filtragem da secretaria poderia ser excluída do processo.

Em terceiro lugar, cabe indagar se é necessária a distinção entre ONG's nacionais e internacionais no processo de admissão de observadores. Muitas ONG's nacionais participam de redes internacionais ao mesmo tempo em que ONG's internacionais possuem filiais nacionais. Nesse sentido, torna-se cada vez mais difícil distinguir as ONG's em nacionais e internacionais. De outro lado, as questões abordadas na CITES envolvem o comércio internacional e, portanto, são de interesse de mais de um Estado. Todavia, isso não impede que uma ONG nacional possa produzir informações úteis ao regime jurídico da CITES.

Em quarto lugar, é esperado enquanto dever das organizações parceiras uma contribuição de forma regular e com habilidade para o desenvolvimento das políticas e instrumentos técnicos e científicos da Convenção, sobretudo no acompanhamento das Partes para satisfazer as suas obrigações decorrentes da Convenção. No entanto, é preciso admitir que existem dois círculos de ONG's na CITES. Assim, as ONG's do círculo interno que possuem relações mais estreitas com o secretariado alcançam maior credibilidade, por exemplo, a IUCN, WWF e TRAFFIC, e consequentemente influenciam mais significativamente no processo. $\mathrm{O}$ círculo externo é formado por todas as outras ONG's. Para minimizar a preocupação com a falta de equidade na representação, ampliando-se a base de ONG's que realizam projetos, o secretariado poderia ser incentivado a subcontratar as demais ONG's, por exemplo, incorporando regras de equidade na licitação.

Finalmente, a questão do financiamento dos países em desenvolvimento. Muito embora não exista formalmente a divisão norte-sul no âmbito da CITES, tal como existe em outros acordos multilaterais ambientais, é preciso atentar para o fato de que as ONG's dos países em desenvolvimento tendem a ser sub-representadas. Nesse sentido, um mecanismo de financiamento destas organizações patrocinado pelas Partes na CITES seria bem-vindo. Tal como estabelecido no artigo 9 (a) do Anexo às regras de procedimento na Convenção sobre Mudanças Climáticas, em que há um fundo complementar, gerido pelo chefe do secretariado da Convenção, que apoia a participação de alguns representantes de organizações não governamentais de países Partes em desenvolvimento, em especial nas sessões da Conferência das Partes.

Esses aspectos ou anomalias exigem de fato estudos mais aprofundados. No entanto, haja vista as tendências inauguradas pela CITES, em especial pela codificação de novas regras evolutivas de participação com base no forte consenso histórico de que as ONG's são importantes parceiras nas formulação e implementação dos regimes internacionais ambientais, pode-se 
esperar que novos desenvolvimentos neste regime ocorrerão e poderão vir a se tornar paradigmas para outros tantos regimes multilaterais ambientais em construção.

\section{REFERÊNCIAS BIBLIOGRÁFICAS}

ANNAN, Kofi. The Quiet Revolution. In: Global Governance. N. 4, 1998.

BERNSTEIN S. Legitimacy in Global Environmental Governance. In: Journal of International Law and International Relations 1, 2005.

BODANSKY, Daniel. The Legitimacy of International Governance: A Coming Challenge for International Environmental Law? In: The American Journal of International Law. Vol. 93, N. 3, 1999.

BOMBAY, Peter. The Role of NGOs in Shaping Community Positions in International Environmental Fora. In: Review of European Community and International Environmental Law. Vol. 10, N. 2, 2001.

CHARNOWITZ, S. Two centuries of participation: NGOs and international governance. In: Michigan Journal of International Law, N. 18, 1997.

COHEN, Jean L. Sociedade Civil e Globalização: repensando categorias. In: DADOS - Revista de Ciências Sociais. Vol. 46, N. 3, 2003.

CONCA, K. Greening the UN: Environmental Organizations and the UN System. In: WEISS, T. G.; GORDENKER, L. NGOs, the UN, and Global Governance. Colorado: Lynne Rienner, 1996.

EDWARDS, Michael. NGO rights and responsibilities: A new deal for global governance. London: The Foreign Policy Centre, 2000.

GEMMILL, B.; BAMIDELE-IZU, A. The Role of NGOs and Civil Society in Global Environmental Governance. In: ESTY, D. C.; IVANOVA, M. H. Global Environmental Governance - Options and Opportunities. Connecticut: Yale School of Forestry \& Environmental Studies, 2002.

HULME, D.; EDWARDS, M. NGOs, states and donors: too close for comfort. New York: St. Martin's Press, 1997.

O'BRIEN, Robert, et alli. Contesting Global Governance. Multilateral Economic Institutions and Global Social Movements. Cambridge: Cambridge University Press, 2000.

ORTIZ, Renato. Mundialização e Cultura. São Paulo: Brasiliense, 1994.

RAUSTIALA, Kal. The Participatory Revolution in International Environmental Law. In: Harvard Environmental Law Review, Vol. 21, 1997.

WIJNSTEKERS, W. The Evolution of CITES. 9. ed. Budapest: International Council for Game and Wildlife Conservation (CIC), 2011. 